\title{
Hibridisme i autoreferència en el fantàstic d'Espiral, de Manuel Baixauli
}

\section{Hybridism and self-reference in the fantastic of Espiral by Manuel Baixauli}

\author{
Carme Gregori Soldevila \\ Universitat de València \\ Carme.Gregori-Soldevila@uv.es
}

\begin{abstract}
The aim of this paper is to define and to analyse the fantastic universe of short stories by Manuel Baixauli published in the volume Espiral (2010), an original and highly significant example of modern fantastic literature that has abolished the real and imaginary borders, that is to say a significant example of fantastic literature conceived as a language phenomenon. The conception of reality integrates and naturalises the supernatural and the irrational in a vision that joins multiple dimensions and perspectives of reality. The self-referential component is also of essential importance in this fantastic, which assimilates and exhibits themes and motifs of inherited traditions in a fully conscious way.
\end{abstract}

Baixauli reflects on the ways of perception and representation of reality, in a proposal in which he combines elements that come from some forms of genre whithin the fantastic tradition. And he does it with full awareness of the linguistic and cultural condition of the referents he uses, exploring implicit meanings, metaphorical value, expectations they generate, etc. A literature that, from the point of view of fantastic literature, opts for hybridism and self-reference.

Keywords: fantastic literature, the fantastic of language, self-reference, Manuel Baixauli, Espiral

Espiral, un recull de 68 microrelats, és la primera obra publicada per Manuel Baixauli, després de guanyar el Premi Ciutat de Badalona 1998. Els textos van ser reelaborats posteriorment i editats de nou en 2010, acompanyats d'un "Epíleg", després de la maduració i de l'èxit assolits amb L'home manuscrit (2007), en una operació de reescriptura adreçada a depurar-ne l'estil i accentuar-ne els mecanismes 
de la brevetat. ${ }^{1}$ Aquesta obra inicial ja conté una part substancial de l'univers característic de l'autor, dels seus motius recurrents i de la seua mirada sobre el món; Baixauli (2010) així ho reconeix a l'"Epíleg": "quan fullege els contes d'Espiral encara m'hi retrobe. [...] El que vull dir és que encara m'identifique amb Espiral, malgrat el temps. L'estil, però, calia depurar-lo" (p. 122). Des d'aquesta perspectiva, Espiral constitueix, doncs, un material idoni per a entendre les bases de la poètica baixauliana. En el present article, ens proposem analitzar-ne un dels components clau: la concepció del fantàstic, així com les funcions que aquest té en la literatura de l'escriptor i els motius en els quals es concreta en aquest recull de microrelats.

\section{LES DIMENSIONS DE LA REALITAT}

El concepte de "real" és essencial a l'hora de fixar el valor i el sentit del concepte de "fantàstic". Todorov (1970) ja va advertir que, a diferència del fantàstic clàssic, la literatura del sobrenatural en el segle XX responia a un procés d'adaptació o de pas del sobrenatural al natural, un procés invers i simètric a l'hesitació que havia caracteritzat el fantàstic del segle XIX, la qual, com a preparació de l'esdeveniment insòlit, exigia un moviment del natural al sobrenatural (p. 179-180). Aquest canvi era la conseqüència inevitable de la transformació operada en la manera de concebre la realitat en el trànsit d'un segle a l'altre:

Le XIXe siècle vivait, il est vrai, dans une métaphysique du réel et de l'imaginaire, et la littérature fantastique n'est rien d'autre que la mauvaise conscience de ce XIXe siècle positiviste. Mais aujourd'hui, on ne peut plus croire à une réalité immuable, externe, ni à une littérature qui ne serait que la transcription de cette réalité. Les mots ont gagné une autonomie que les choses ont perdue. (Todorov, 1970, p. 176-177)

Així, doncs, la nova concepció de la realitat integra i naturalitza el sobrenatural i l'irracional en una visió que suma múltiples dimensions i perspectives del real. El fantàstic s'hi ha generalitzat: ja no n'és l'excepció, sinó la regla (Todorov, 1970, p. 182). Posteriorment, altres estudiosos del fantàstic, com Jaime Alazraki (1983), Jean Fabre (1992) o Mery Erdal Jordan (1998), han insistit a remarcar l'abolició de fronteres entre real i imaginari com a tret distintiu del fantàstic modern -en terminologia d'Erdal Jordan (1998, p. 110)-, en contraposició a la dialèctica real/irreal pròpia del fantàstic tradicional. Com conclou David Roas (2011), "la realidad ha dejado de ser una entidad ontológicamente estable y única y ha pasado a contemplarse como una convención, una construcción, un modelo creado por los seres humanos", motiu pel qual "ya no puede concebirse (reconstruirse) un nivel absoluto de realidad, un criterio definitivo o infalible de esta" (p. 28).

\footnotetext{
${ }^{1}$ En el present treball, seguirem l'edició de 2010.
} 
En ocasions diverses, Baixauli ha deixat constància de participar d'aquesta creença en una realitat àmplia $\mathrm{i}$ inclusiva, dotada de múltiples dimensions; un ordre del món inconcebible des de la lògica racional. És el cas, per exemple, de l'article "Altres mons", pertanyent a la sèrie "Focs perdurables", en la qual l'escriptor va anar inventariant les principals influències artístiques del seu univers literari. En relació als volums de la col·lecció La Biblioteca de Babel, dirigida per J. L. Borges, Baixauli (2009a) revela la seua descoberta d'una realitat literària que havia d'anar més enllà de les limitacions de la poètica realista:

Aquells llibres parlaven no de quimeres artificioses, com poden creure els lectors afectats de realitosi, sinó de veritats subterrànies, subtils, mentals, més profundes i significatives que la superfície enganyosa de les coses. [...] Aquells textos em convenceren que jo havia d'escriure sense parar-me a diferenciar entre personatges vius o morts, temps passats, presents o futurs, espais materials o mentals; a expressar-me, en definitiva, amb una llibertat sense límits, empès, només, per la recerca de la seducció i la bellesa. (p. 19)

O, en L'home manuscrit, s'interroga sobre el contrasentit que representaria sotmetre's a les restriccions d'una oposició entre real i imaginari:

Quimèriques?... [les històries que li agrada escriure]. No són reals els nostres somnis i malsons? No esdevé real allò que som capaços d'imaginar? Què són la Divina Comèdia, el Gargantua, el Moby Dick, les Mil i una nits, les obres d'Homer, Poe, Stevenson, Kafka o Borges, sinó somnis o malsons? Hem de limitar-nos a allò visible, superficial, epidèrmic?... (Baixauli, 2007, p. 170)

Per aquest motiu, en alguns contes d'Espiral, la transició entre la realitat objectiva i el somni o el desig es realitza sense fractures, com s'esdevé amb la materialització del desig del protagonista de "Lluny" o el no retorn del somni de la dona d'"Eclipsi". La crítica ha posat èmfasi en aquesta exploració dels límits del real: per a Vicenç Pagès Jordà (2010), una part significativa dels relats indaguen sobre la realitat a través de la ruptura d'una frontera generalment acceptada (p. 65); per a Enric Sòria (2010), per la seua banda, es refereixen a "aquell pertorbador territori que s'agita entre el somni i la vetlla i que és l'autèntica geografia de la literatura de Baixauli" (p. 4).

Una de les dimensions de la realitat és la de la mort, motiu elaborat de maneres molt diverses $\mathrm{i}$ recurrent en l'univers de Baixauli, ${ }^{2}$ que s'hi fa present com una presència perceptible en la nostra quotidianitat. Els morts -éssers estimats o persones conegudes que hem perdut- $s$ 'integren en la nostra experiència del món, propers i familiars. Si en l'article "Fora del temps" la trobada amb els difunts és una

\footnotetext{
${ }^{2}$ En l'article "Fora del temps", Baixauli (2009b) confessa l'obsessió per la mort i reconeix: "la mort: omnipresent, des d'un principi, en els meus insignificants quadres i dibuixos, en els meus insignificants escrits" (p. 18).
} 
evocació provocada per la suggestió de la música i el poder de la memòria (Baixauli, 2009b, p. 19), en la ficció narrativa l'autor materialitza el record i els presenta com a figures instal-lades en el paisatge d'una manera harmònica i natural, sense ombra de basarda: a "Diari", el narrador topa amb amics i familiars morts en els seus passeigs quotidians, $i$ ens els presenta com a éssers savis d'actitud serena; a "Visita", els morts i els vius parlen i gesticulen, barrejats, al terrat del narrador; a "Parxís", el narrador retroba els pares, ara difunts, en la casa de la platja, en una escena que recupera el record del passat compartit. A més, l'autor es complau a esborrar les barreres entre ficció i realitat quan trasllada aquesta mateixa convivència entre vius i morts al paratext. En l'“Epíleg" introduït en l'edició revisada, un postfaci clarament auctorial (v. Genette, 1987, p. 166), Baixauli (2010) fa servir un diàleg entre ell i el Baixauli que va escriure la primera versió d'Espiral anys enrere com a recurs per a explicar els motius i l'abast de la reelaboració de l'obra i, en aquest context, introdueix la presència del pare, ja desaparegut, que anuncia que el sopar està llest; l'autor, apunta: "des de l'octubre del 2005, en què va morir, que no el veia" (p. 124). Igualment, a La cinquena planta, Baixauli (2014) atribueix a un dels personatges aquesta mateixa convicció: "ell deia que els carrers no eren mai buits, que, per poc que t'esforçares, s'hi intuïen els veïns desapareguts durant els últims anys" (p. 22).

Aquesta realitat multidimensionada, com és lògic, depèn més dels mecanismes de la fabulació que de les estrictes lleis de la Física i, per tant, es concreta, molt sovint, en alteracions del temps i de l'espai. A "Foto", l'home que es contempla en l'escena fixada en la fotografia de la seua infantesa té el seu paral·lel en el nen de la fotografia que mira l'home adult que l'esguarda. L'abolició del temps com a progrés linial permet situar en un pla d'igualtat i dotar de consciència dos moments d'una mateixa existència. "Piscina", per la seua banda, seria un exemple de mutació espacial, amb la transformació de l'espai familiar i acollidor en què transcorre un moment d'oci en un altre d'hostil i aterrador, sense punt d'inflexió ni solució de continuïtat.

En la proposta de Baixauli (2010), la representació de la realitat també pot constituir, per ella mateixa, la realitat, com podem apreciar a "Fi", on el científic, amb el baló que reprodueix un mapamundi, "ignorant que té a les mans la Terra vertadera, i que l'examina des d'un equívoc reflex, [...] empeny l'agulla i aniquila tot senyal de vida sobre el món" (p. 90).

La concepció d'una realitat que integra i naturalitza percepcions diverses -excloents i contradictòries des d'una òptica cientifista- té la seua correspondència literària en una poètica que assimila en pla d'igualtat models i influències igualment diversos. Si la fabulació se situa al mateix nivell que el real, és coherent pensar que els productes de la imaginació constitueixen uns referents susceptibles de convertirse en matèria literària. Més encara, la ficció literària, en el fantàstic modern, posa de relleu una forta autoreferencialitat, ${ }^{3}$ en remetre de manera constant als tòpics de la

\footnotetext{
${ }^{3}$ Maria Dasca (2016) ha assenyalat que els tres elements claus en l'elaboració de la realitat en la narrativa de Baixauli són: "l'autoreferencialitat, el desdoblament espectral i la metaficció" (p. 57).
} 
tradició fantàstica, anivellant, en un hibridisme característic, temes, motius i tractaments procedents de diferents orígens. És el fantàstic del llenguatge, en terminologia d'Erdal Jordan (1998), que pretèn "relativizar la noción de realidad enfatizando el papel modelizador que cumple el lenguaje en su construcción", de manera que supedita "la captación de la realidad a su articulación lingüística" (p. 142).

En aquest sentit, Alfons Gregori (2015) recorda oportunament que, en l'època de la postmodernitat, el gènere fantàstic proveeix un conjunt ampli de materials $i$ de recursos que coexisteixen, com a referents, en una configuració dinàmica: "la tradición literaria forma capas superpuestas de motivos, procedimientos, temas y otros aspectos formales en contacto contínuo, capas que ejercen entre sí una dialéctica que redunda en la creación final por parte de los autores" (p. 196).

\section{ELS DIFERENTS MODELS DEL FANTÀSTIC A ESPIRAL}

El fantàstic no rau en l'esdeveniment extraordinari, sinó en una mena de percepció (Todorov, 1970, p. 97) i, per aquest motiu, entès en un sentit ampli, s'ha diversificat en subgèneres i productes singulars que, al seu torn, han fixat d'una manera particular els tòpics basats en el sobrenatural o l'estrany. En Espiral, les orientacions i el tractament de l'extraordinari són múltiples, amb un ventall de referències literàries que abasten gairebé tots els registres de la tradició fantàstica. En tant que construccions imaginàries i discursives, l'univers baixaulià els atorga un idèntic rang de realitat. Es tracta, en tots els casos, de figures, temes i relats que li permeten bastir el propi edifici literari, amb un hibridisme característic que les conjuga i barreja en una proposta original.

Podem assenyalar, en primer lloc, el fantàstic estricte que, seguint la proposta de Todorov (v. 1970, p. 37), trobem a "Migdiada": el dubte entre l'explicació natural del fenomen -el malson- i l'explicació sobrenatural que queda apuntada al final del microrelat, amb la sang i la carpeta de factures que semblen avalar la mort del jove cobrador, causada per les formigues gegants, connecta aquest conte amb l'hesitació que el teòric estructuralista exigeix al fantàstic pur. ${ }^{4}$

El meravellós o sobrenatural acceptat (v. Todorov, 1970, p. 57-62) apareix a "Tres", un conte que, significativament, distancia les coordenades espaciotemporals i presenta un món exòtic, on els prodigis no posen en qüestió la realitat del lector, el qual n'encara la lectura des de la suspensió de la incredulitat. D'altra banda, també hi podem rastrejar exemples que hem de posar en relació amb una altra mena de meravellós, designat com a preternatural per Jean Fabre (1992): un seguit de motius que encarnen creences paganes o supersticioses en la cultura popular

\footnotetext{
${ }^{4}$ La importància de l'ambigüitat com a element nuclear del fantàstic també ha estat assenyalada per altres estudiosos del gènere, com Gregori (2015): "la ambigüedad es el eje de lo fantástico, sea por lo inexplicado o por lo inexplicable" (p. 199).
} 
(p. 67). En concret, ens estem referint, sobretot, a dos microrelats centrats en la figura de l'esperit tutelar que ve del més enllà per a avisar d'un perill i en la del personatge que apareix per a anunciar la mort d'algú (v. Martín Sánchez, 2002, p. 413-420): "Camió" i "Criatura", respectivament. En aquest segon, la presència de la xiqueta que prediu la mort dels veïns als quals segueix es vincula explícitament a una tradició arrelada en el poble: "el meu avi ja ho contava" (Baixauli, 2010, p. 79), afirma el cambrer, per a certificar-ne l'antiguitat. "Camió”, per la seua banda, representa un gir desmitificador en relació al model perquè l'avís de la mort resulta completament inútil.

Però, sens dubte, el registre dominant a Espiral és el de l'estrany, una categoria més imprecisa que el fantàstic, que, en opinió de Todorov (1970), es correspon tant amb el sobrenatural explicat com amb la literatura d'horror o el relat d'experiències límit (p. 49-54). D'aquesta manera, a l'igual com s'esdevé amb el fantàstic, allò que caracteritza l'estrany és la reacció de por o d'inquietud que els fets provoquen en el personatge i en el lector, més que no pas uns esdeveniments que desafien l'ordre racional (Todorov, 1970, p. 52). Cal recordar, igualment, que l'unheimliche freudià designa, encara que atribuint-li unes causes ben precises en l'experiència psíquica, aquesta mateixa estranyesa inquietant, vinculada per Freud (1974) a un repertori de motius temàtics que inclouen l'aparició de morts, el doble, l'animació d'objectes inanimats, l'omnipotència de pensament, la repetició involuntària i els òrgans tallats (p. 2488-2500).

En Espiral, l'estrany es concreta en l'experiència dels límits -una modalitat que té en l'obra d'E. A. Poe un dels seus referents principals (Todorov, 1970, p. 53-54)$\mathrm{i}$ en diverses mostres de literatura d'horror. La presència inquietant del personatge que ha assetjat la dona de "Testimoni", amb la seua mirada fixa, en ocasions diverses al llarg de la seua vida o la de la vella estranya i silenciosa de "Fruita" poden atribuir-se a l'atzar d'una casualitat o, en el primer cas, fins i tot podria tractar-se d'un error de percepció de la protagonista. També podria tractar-se d'una distorsió dels fets per part del personatge allò que s'esdevé a "Broma": la primera impressió de sentir-se extraviat sembla reduir-se en ser acollit en una casa on hi ha reunit un grup de veïns, vagament familiar per al protagonista; però l'estranyesa va guanyant terreny, a pesar de l'atmosfera "distesa i festiva" (Baixauli, 2010, p. 31) i l'home se sent inquiet perquè els veïns li semblen "molt més alts i prims" del que recordava i l'estatura continua augmentant en relació a la seua, alhora que aquesta sensació s'acompanya de la reacció freda, fins i tot mortificadora, dels amfitrions. L'aventura narrada a "Novel·la" per la seua banda, presenta uns fets extraordinaris, en el sentit d'excepcionals, que podrien semblar propis d'una dimensió paral·lela per la seua raresa i pel desassossec que provoquen, si no fos que res més no avala aquesta hipòtesi: en un paratge solitari, un adolescent singular escriu una novel·la que relata esdeveniments encara per arribar que, passats els anys, el futur confirmarà; el narrador testimoni serà incapaç de tornar a trobar la casa i el seu habitant, però l'expe- 
riència potser només té un efecte pertorbador perquè amenaça de forçar els límits que la raó humana és capaç d'acceptar.

Per a altres teòrics, en canvi, que mantenen una concepció recepcionista del fantàstic (v. Gregori, 2015, p. 73-84), aquest és el gènere -i no estrictament l'estranyque ha d'anar necessàriament lligat a la por. Per a Lovecraft (1973), una de les referències ineludibles quan parlem de literatura d'horror, però igualment teòric d'aquest gènere, l'element decisiu per a l'obtenció de l'efecte desitjat en allò que denomina "supernatural horror-literature" és la creació de l'atmosfera:

Atmosphere is the all-important thing, for the final criterion of authenticity is not the dovetailing of a plot but the creation of a given sensation. [...] Therefore we must judge a weird tale not by the author's intent, or by the mere mechanics of the plot; but by the emotional level which it attains at its least mundane point. [...] The one test of the really weird is simply this -whether or not there be excited in the reader a profound sense of dread, and of contact with unknown spheres and powers. (p. 16)

Altres teòrics posteriors del gènere, com Roas (2011), n'han mantingut com a tret definitori la reacció de por o d'inquietud que ha de produir en els personatges i en el lector:

El miedo es una condición necesaria para la creación de lo fantástico, porque es su efecto fundamental, producto de esa trangresión de nuestra idea de lo real sobre la que vengo insistiendo. Por eso todo relato fantástico - contradiciendo a Todorov- provoca la inquietud del receptor. (p. 88)

"Canícula" i "Forat" són dos dels exemples més significatius del registre d'horror a Espiral. En el primer, l'alta temperatura del ple estiu i la soledat contrasten, d'entrada, amb la calma aparent i contribueixen a crear una atmosfera sinistra que esclatarà amb el cop d'efecte final, quan descobrim que l'enterrador d'altra banda, fidel a la funció que li pertoca exercir- ha enterrat viu a l'ossari el jove estudiant de medicina que hi buscava un crani. "Forat", d'altra banda, podria entendre's fins i tot des d'una perspectiva d'horror sobrenatural, perquè cap tret no identifica l'ésser ocult que talla el coll de l'excursionista curiós que ha introduït el cap pel forat d'una estranya construcció, la qual s'erigeix incomprensiblement en una plana remota del paisatge muntanyenc. Cal parar esment, però, que aquest ésser emergeix al final del conte com a narrador dotat d'un coneixement sense restriccions de la vida i pensaments de l'infortunat jove, un fet que només es pot entendre si li atribuïm un caràcter omniscient, incompatible amb un narrador personatge sense qualitats sobrenaturals.

El recull de microrelats de Baixauli inclou una mostra significativa de textos que, de manera específica, cal situar en l'òrbita d'allò que Erdal Jordan (1998) denomina el fantàstic com a fenomen del llenguatge, és a dir, aquell que explota la problematització de la concepció convencional de la realitat mitjançant el recurs de 
juxtaposar-hi l'imaginari lingüístic, amb un marcat component d'autoreferència: els procediments que fa servir aquest fantàstic del llenguatge són la impertinència semàntica i la metalepsi (p. 112).

En el cas de la impertinència semàntica, la infracció de la percepció convencional de la realitat se situa a nivell estrictament lingüístic, sense dependències mimètiques, i posa així de manifest la preponderància del llenguatge en la captació i creació de realitat. Com ha assenyalat Erdal Jordan (1998), aquest fantàstic acusa una forta consciència metaliterària perquè explota els sentits latents de les figures del llenguatge: elabora uns fenòmens sobrenaturals que són assumits amb naturalitat a partir de l'accepció literal de les figures, que ve a substituir l'habitual sentit figurat (p. 114). Així, implanta l'imaginari de caràcter lingüístic com una realitat alternativa, posant èmfasi en l'autonomia del llenguatge $i$ en la capacitat que té per a bastir mons desvinculats del món real (Erdal Jordan, 1998, p. 116-117).

El microrelat "Espiral", especialment destacat perquè tanca i dóna nom al recull, pertany a aquest grup; sense perdre un acusat caràcter metaforicosimbòlic, desenvolupa la història a partir de la interpretació literal de la figura retòrica que proposa la immensa caragola com a representació de la vida humana: com a destí final, com a espai de transició entre el silenci del desert previ i l'oceà de l'oblit al qual aboca. ${ }^{5}$ La transferència de sentit del conte al recull que transmet el títol compartit permet plantejar la hipòtesi que el viatge es puga entendre també aplicat a l'experiència que el lector es disposa a emprendre. El símbol de la caragola reapareix a La cinquena planta, en un dels aforismes de Timoteu, també amb un sentit que és possible remetre a l'existència humana, com una representació de les vides possibles que hi ha dins cada vida: "dins la caragola hi ha una mar. Dins la mar, infinites caragoles amb una mar a dins" (Baixauli, 2014, p. 252). Un dels contes que té una certa similitud amb "Espiral" és "Escala", on la representació metafòrica de la vida adopta la forma d'un recorregut inacabable i sense sentit; l'individu avança amb dificultat, sense saber on acabarà ni poder tornar enrere, amb l'atracció de l'abisme sempre present.

A "Infància", el gegant que devora un vell casal modernista envoltat de jardí és un altre dels exemples que conserven el valor figurat, tot i desenvolupar de manera literal en la diegesi la metàfora del progrés destructor dels paisatges de la infantesa. En la mateixa línia, "Panteó" materialitza a nivell corporal, en una "proliferació de pòlips" (Baixauli, 2010, p. 63), els records i les vivències del personatge, revelats per les incisions del cirurgià que els alliberen.

El desenvolupament literal, a nivell d'història, de l'expressió figurada funciona com a impuls, estrictament lingüístic, de la fabulació d'“Aire". Si, en un primer

\footnotetext{
${ }^{5}$ La desaparició i l'oblit com a futur indefugible és una de les obssessions recurrents en l'univers baixaulià. En Espiral, ho podem constatar especialment a "Brindis", però apareix igualment enunciat a l'article "Fora del temps" (Baixauli, 2009b, p. 18) o en La cinquena planta: "avancem, distrets, dalt d'una cinta mecànica que porta a l'oblit" (Baixauli, 2014, p. 122).
} 
moment, les paraules de l'individu irat que clama contra els habitants del poble: "no teniu res dins sinó aire!", "heu esdevingut tan frívols, tan banals, que us heu quedat buits" (Baixauli, 2010, p. 109) semblen tenir un estricte valor metaföric, la continuació del relat s'encarregarà de mostrar-nos-en el sentit literal i les conseqüències que se'n desprenen quan la pluja torrencial, amb les seues agulles d'aigua, rebente tots els veïns.

"Oceà" mostra el futur que s'oculta sota la placidesa del present a través de la imatge de les grans esferes que s'estimben pel penyasegat; la mirada atenta del narrador ens descobreix que són els caps dels enamorats que viuen -ignorants d'aquesta amenaça- la seua lluna de mel. La innegable dimensió metaforicosimbòlica, una vegada més, no aconsegueix desplaçar la força de la narració d'una història, essencialitzada en una escena, com és propi de la brevetat del gènere, però amb un relat que es desplega a través del sentit latent de la metàfora.

Per la seua banda, "Tracte" s'empara de la naturalització del llenguatge figurat per a dotar de significació alhora el fet extraordinari i el conte: el braç que "creix i es prolonga vertiginosament, sense pausa, fins que la seua figura [la de la persona a qui estrenya la mà] s'allunya tant que la perd de vista" (Baixauli, 2010, p. 43) es converteix en una serp de cascavell per a posar de manifest la distància i l'engany que s'amaguen sota el somriure i l'encaixada de mans que tanquen el tracte.

La metalepsi és un qüestionament dels nivells narratius, un concepte que ha estat definit per Genette (1983) com "cette transgression déliberée du seuil d'enchâssement" segons la qual "un auteur (ou son lecteur) s'introduit dans l'action fictive de son récit ou $[\ldots]$ un personnage de cette fiction vient s'immiscer dans l'existence extradiégetique de l'auteur ou du lecteur" (p. 58). Si bé en aquesta definició Genette parla estrictament de ficcions narratives, en un estudi monogràfic posterior, Métalepse. De la figure à la fiction (2004), eixampla el camp d'acció de la metalepsi a altres modalitats d'expressió artística, com la pintura, el teatre o el cinema. En tant que transgressió de les convencions literàries, la metalepsi és un recurs eficaç al servei de la metaficció perquè obliga a reflexionar sobre el concepte mateix de ficció i sobre les relacions que aquesta ficció estableix amb la realitat. En paraules de Patricia Waugh (1984), la metaficció "is a term given to fictional writing wich selfconsciously and systemalitally draws attention to its status as an artefact in order to pose questions about the relationship between fiction and reality" (p. 2).

"Intrús" i "Camí" constitueixen dos interessants casos de metalepsi a Espiral. En el primer, el visitant del Museu del Prado penetra inadvertidament en el quadre Las Meninas de Velázquez. El famós quadre no és esmentat pel seu títol, però sí inequívocament descrit: "una estança en penombra, on un cavaller pintava un llenç enorme, amb unes criatures xaparres, anacrònicament vestides, i un gos per models"

\footnotetext{
${ }^{6}$ El quadre de Velázquez també presenta una metalepsi, a la qual s'ha referit Genette (2004) en el seu estudi, amb la introducció dels personatges pertanyents al món exterior que apareixen reflectits a l'espill (p. 74).
} 
(Baixauli, 2010, p. 92). La metalepsi queda definitivament certificada d'una manera tan efectiva com enginyosa: l'intrús descobreix que, a l'espill que hi ha a l'estança, en comptes de veure-hi reflectida la pròpia imatge, es troba amb uns turistes japonesos que l'observen atònits. Per descomptat, la sorpresa d'aquests turistes dóna fe del trencament de nivells, de la realització de la -en principi- impossible penetració de l'espectador real en l'escena reproduïda en la pintura. ${ }^{7}$ En el segon conte, la metalepsi no és explícita, però s'apunta com a interpretació plausible: la penetració del pintor en el quadre a la recerca de la seua infantesa.

"Anunciació" i "Aniversari" no poden considerar-se exemples de metalepsi, però els dubtes que instauren sobre la naturalesa de les relacions entre la realitat i les seues formes de representació té un innegable valor metaficcional, i, en aquest sentit, responen a una idèntica concepció de la literatura, que té les pertinents conseqüències en la naturalesa dels mons de fícció que li són propis. En el primer cas, la biografia del pintor que apareix a l'enciclopèdia -una clara mostra de representació de la vida del pintor- avança esdeveniments encara no viscuts pel personatge, en particular, la forma i l'any de la mort. El biografiat ho interpreta com una burla i, de manera inconscient, es llança a convertir en realitat l'anunci. Estem al davant d'un exemple que ha capgirat per complet les relacions entre realitat i representació que dominaven l'estètica realista: si, per al Realisme, la representació havia de ser un reflex mimètic de la realitat, ara, per contra, ens trobem amb una realitat que copia la seua pròpia representació. "Aniversari" incideix igualment en la naturalesa de les relacions entre realitat i representació; en aquest cas, per a crear-hi una ambigüitat: la broma macabra de representar el suïcidi de l'amic en l'aniversari de la mort acaba amb la mort del bromista en les mateixes circumstàncies. Allò que comença com a simulacre acaba com una dramàtica realitat.

\section{ELS MOTIUS DEL FANTÀSTIC A ESPIRAL}

El rastre del fantàstic també es pot detectar a Espiral en l'àmbit dels tòpics o motius temàtics fixats pel gènere i esdevinguts característics. El doble, un dels temes recurrents de la tradició fantàstica, va encarnar en el Romanticisme la crisi d'identitat, d'estranyesa amb si mateix, del subjecte coetani. La literatura fantàstica clàssica el va prendre com a representació de l'individu que, en paraules de Silvia Albertazzi (1993), "ha ormai perso l'armonia con se stesso e con il creato e aspira, invano, a recuperare quell'interezza" (p. 27), i va llegar el tòpic a la literatura posterior, en la qual la recreació del doble adquireix una inevitable dimensió hipertextual, una consciència, compartida amb el lector, dels models que imita o transforma.

\footnotetext{
${ }^{7}$ Maria Dasca (2016) estudia aquest exemple dins l'apartat que dedica a l'autoreferencialitat i l'explica com un cas de doble mise en abîme (p. 59-60).
} 
Goimard i Stragliati (1977) consideren que la figura del doble pot encarnar-se en dos desenvolupaments principals: el doble perdut, que és un doble per divisió, i el doble trobat, que és un doble per multiplicació (p. 17). Un dels microrelats del recull baixaulià, "Ajust" s'ha d'entendre com un clar exemple del primer tipus, amb la imatge reflectida en l'espill com a representació de l'altre, en una concepció escindida del jo. L'altre hi és percebut com un ésser aliè i hostil, tal com prescriu el gènere; com algú que irrita i desperta un sentiment d'incomprensió, però, tot seguit, el canònic desenllaç tràgic hi és substituit per l'autocrítica i la comprensió d'un jo que accepta la raó del doble. La concepció de l'individu que penetra amb el segle $\mathrm{XX}$, tot i reconèixer-ne la dissociació, es resol en l'acceptació de la duplicitat com a veritable identitat (Albertazzi, 1993, p. 27-28). "Reflex", per la seua banda, pertany a les històries de dobles per multiplicació: el protagonista troba casualment algú que se li assembla extraordinàriament; l'entusiasme inicial, deixa pas, primer, a la inquietud i, finalment, a la desesperació i a l'assumpció de la derrota. Com acostuma a passar en les històries de dobles del fantàstic, el doble hostil representa una amenaça per a la identitat del jo i l'aboca a una situació insostenible; com ha assenyalat Mellier (2000), "la copie cherche à expulser l'original qui ne peut se libérer qu'en cherchant à exterminer le double" (p. 59). Paradoxalment, però, el desenllaç habitual en el fantàstic resol que l'impuls de destrucció del doble, com a reacció d'autodefensa, desemboca en la pròpia autodestrucció. En el conte de Baixauli observem com el doble destructiu s'apropia de la vida del personatge: n'usurpa la identitat i el deixa sense família, sense casa, sense feina. En "Reflex", la mort física és substituïda per la derrota civil i moral d'un jo que, substituït i arraconat pel doble, acaba assumint la situació d'exclusió i la pèrdua d'identitat. En aquest cas, per tant, la destrucció del jo víctima no arrossega la del doble perseguidor. La presència del doble a Espiral llisca dels textos de ficció al prefaci auctorial, amb un efecte de subratllat semblant a l'observat en parlar de l'existència dels morts en el món dels vius. El desdoblament entre l'autor i el seu jo del passat, malgrat l'indubtable sentit metafòric, s'hi presenta de manera assertiva, sense ombra de vacil·lació, motiu pel qual contribueix a configurar l'atmosfera característica del recull i a precisar la poètica de l'autor.

El fenomen de l'animació de l'inanimat apareix tant en la literatura fantàstica com en la tradició del meravellós, amb un tractament diferenciat en cada cas. En el meravellós, la causalitat de l'animació és d'origen sobrenatural i, d'acord amb les lleis del gènere, no provoca cap mena d'inquietud o de dubte sobre la seua realitat, mentre que en el fantàstic els objectes $i$ les figures animats adquireixen una càrrega amenaçadora, envoltats per una ambigüitat a l'entorn de la seua realitat que és el factor principal de l'atmosfera inquietant que s'hi genera. Els dos exemples que aplega Espiral s'emparenten clarament amb el gènere fantàstic. "Marbre" en recrea un dels motius habituals: la figura antropomòrfica (v. Steinmetz, 2008, p. 28-30) que, pel seu caràcter de reproducció, facilita la indeterminació entre l'ésser viu i la 
seua representació. En aquest cas, es tracta d'una escultura, una opció que compta amb il·lustres referents en la creació del tòpic, com ara, "La Vénus d'Ille", de Prosper Mérimée. En el conte de Baixauli, l'estàtua de marbre que reprodueix l'home misteriós, l'aparició de la qual ve a coincidir amb la desaparició del model, per a afegir-hi encara més misteri, desembocarà en un incident -la fractura d'un dit que sagna- que imposa l'aterradora qüestió de la naturalesa inanimada o viva de l'escultura. La succinta descripció del fenomen que tanca el conte, pròpia de la brevetat que governa el gènere del microrelat, encara contribueix a acrèixer la cercada impressió d'ambigüitat. L'altre exemple d'animació de l'inanimat el trobem a "Lot", on el tòpic adopta el desenvolupament que podem denominar "la revolta dels objectes". Un acte quotidià, aparentment banal, com és desfer-se d'una cadira trencada, acaba en assassinat perquè la resta de mobles reaccionen davant la separació amb l'actitud de defensa i el sentit de pertinença al grup propis d'un ésser viu. Una vegada més, el fantàstic naix del llenguatge: el comentari suposadament anodí del venedor, que compara el lot de mobles a una família i presenta com un crim la possibilitat de separar-los, funciona com a causalitat d'un esdeveniment fantàstic que no fa més que prendre aquesta consideració en termes literals i actuar en conseqüència.

El tractament fantàstic de la metamorfosi, a diferència del mite i del meravellós, es concentra més en la transformació mateixa que en els seus resultats perquè és l'instant on l'ordre del real posa a prova els seus límits (Steinmetz, 2008, p. 33). "Gavines" segueix estrictament aquesta orientació, amb la descripció del trànsit home-gavina com a únic objectiu de la narració, sense interrogar-ne les causes i sense interessar-se'n pels efectes.

Com ja hem advertit en parlar de les dimensions de la realitat en l'univers de Baixauli, la mort n'és un motiu omnipresent, que s'hi presenta elaborat de formes diverses, no necessàriament de caràcter sobrenatural o extraordinari. Entre les creacions que cal posar en relació amb la tradició fantàstica, hi destaquen aquelles que tenen com a protagonistes éssers fantasmagòrics, com "Criatura", ja comentat. Un altre dels exemples representatius és "Deute", que actualitza el motiu de l'espectre vindicador que apareix per a exigir la reparació d'una falta. Més que d'un mort, en sentit estricte, en el conte de Baixauli l'aparició és la d'un infant, el qual, en col-laboració amb el seu jo adult, durà a terme la revenja de l'ofensa soferta en el passat. En aquesta ocasió, la raó de ser del fantasma s'ajusta a un dels tipus perfectament fixats per la tradició fantàstica: la de l'espectre perseguidor que té per missió la venjança (v. Sadoul, 2001, p. 6-10).

L'ordre racional del món fonamenta, en gran mesura, la seua veritat en l'estabilitat de les coordenades espaciotemporals, com a garanties indispensables per a situar l'experiència de la realitat: un món en ordre implica necessàriament una successió temporal sense salts i un espai inalterable. És per aquesta raó que la literatura fantàstica, amb intenció de qüestionar la seguretat d'aquest ordre, ha convertit 
les alteracions de temps i espai en matèria literària. En relació a Espiral, ja ens hi hem referit, com un efecte derivat de les múltiples dimensions de la realitat i com a casos de metalepsi. Als exemples ja ressenyats podem afegir ara els d'"Imant", "Avís" i "Desert".

\section{CONCLUSIONS: HIBRIDISME I AUTOREFERÈNCIA}

Espiral acull un ventall de tòpics i de concepcions provinents de diferents subgèneres de la tradició fantàstica, entesa, en un sentit ampli, com aquella literatura que ha fabulat l'extraordinari o el sobrenatural. En tant que producte d'un fantàstic modern o fantàstic del llenguatge, el principal criteri de selecció es basa en el reconeixement de l'autonomia significativa del sistema lingüístic i en la consciència metaficcional. Per això, els models heretats de la tradició fantàstica, amb els seus diferents registres i tòpics, hi són entesos com a realitats lingüístiques i imaginàries i s'hi assimilen en un hibridisme característic.

Si la propensió autoreferencial sembla consubstancial al fantàstic perquè el fet fantàstic no té cap altra referència que l'experiència mateixa del text o el camp imaginari, cultural o arxitextual (Mellier, 2001, p. 17), aquesta propensió esdevé manifesta en la modalitat del fantàstic del llenguatge. El fantàstic de Baixauli és un fantàstic autoreferent perquè el seu univers de referència remet, de manera conscient, premeditada i definitòria, a la literatura mateixa, a un horitzó d'expectatives i un conjunt de trets identificables en termes de corpus de gènere (v. Mellier, 2001, p. 18). El sentit de contradicció només té cabuda en una poètica que descanse en una dialèctica real/irreal, ja superada. Baixauli, per contra, naturalitza i fa seues, en una proposta original, unes construccions del fantàstic que comparteix amb el lector com a part d'una realitat que la seua literatura prova d'entendre. 


\section{REFERÈNCIES BIBLIOGRÀFIQUES}

Alazraki, J. (1983). En busca de l'unicornio: los cuentos de Julio Cortázar. Elementos para una poètica de lo neofantástico. Madrid: Gredos.

Albertazzi, S. (1993). La letteratura fantastica. Roma \& Bari: Laterza.

Baixauli, M. (1998). Espiral. Barcelona: Columna.

- (2007). L'home manuscrit. Palma: Moll.

- (2009a). Altres mons. L'Avenç, 347, 18-19.

- (2009b). Fora del temps. L'Avenç, 348, 18-19.

- (2010). Espiral. Barcelona: Proa.

- (2014). La cinquena planta. Barcelona: Proa.

Dasca, M. (2016). "L'ombra de dins l'ombra de mi mateix". Una indagació en la metaliteratura de l'obra de Manuel Baixauli. Els Marges, 109, 52-67.

Erdal Jordan, M. (1998). La narrativa fantástica. Evolución del género y su relación con las concepciones del lenguaje. Frankfurt am Main \& Madrid: Vervuert \& Iberoamericana.

Fabre, J. (1992). Le miroir de sorcière. Essai sur la littérature fantastique. París: José Corti.

Freud, S. (1974). Obras Completas, VII (1916-1924) (L. López-Ballesteros, trad.). Madrid: Biblioteca Nueva.

Genette, G. (1983). Nouveau discours du récit. París: Seuil.

- (1987). Seuils. París: Seuil.

- (2004). Métalepse. De la figure à la fiction. París: Seuil.

Goimard, J. \& Stragliati, R. (1977). La grande anthologie du fantastique. Histoires de doubles. París: Presses Pocket.

Gregori, A. (2015). La dimensión politica de lo irreal: el componente ideológico en la narrativa fantástica española y catalana. Poznań: Wydawnictwo Naukowe UAM.

Lovecraft, H. P. (1973). Supernatural Horror in Literature (2a ed.). Nova York: Dover Publications.

Martín Sánchez, M. (2002). Seres míticos y personajes fantásticos españoles. Madrid: Edaf.

Mellier, D. (2000). La littérature fantastique. París: Seuil.

- (2001). Textes fantômes. Fantastique et autoréférence. París: Éditions Kimé.

Pagès Jordà, V. (2010, 3 de març). Fantasia existencial. El Periódico, 65.

Roas, D. (2011). Tras los límites de lo real: una definición de lo fantástico. Madrid: Páginas de Espuma.

Sadoul, B. (2001). Introduction. Dins B. Sadoul (ed.), Un bouquet de fantômes (p. 5-12). París: E.J.L.

Sòria, E. (2010, 4 de febrer). Arabescos del temps. El País. Quadern, 4.

Steinmetz, J.-L. (2008). La littérature fantastique (5a ed.). París: PUF.

Todorov, T. (1970). Introduction à la littérature fantastique. París: Seuil.

Waugh, P. (1984). Metafiction. The Theory and Practice of Self-Conscious Fiction. Londres \& Nova York: Routledge. 